\title{
Factors Influencing Anorexia in Elderly Patients in South Korea
}

Chaebong Kim ${ }^{1,5}$, Mooyoung Kim², Seokjun Yoon ${ }^{3}$, Sung wan Hwang ${ }^{*}$

${ }^{1}$ Department of Public Health, Korea University Graduate School, Seoul, South Korea

${ }^{2}$ Department of Family Medicine, Seoul Medical Center, Seoul, South Korea

${ }^{3}$ Department of Preventive Medicine, Korea University College of Medicine, Seoul, South Korea

${ }^{4}$ Department of Health Administration, Baekseok Art University, Seoul, South Korea

${ }^{5}$ Environmental Health Center for Asthma, Korea University Medical Center, Seoul, South Korea

Article Details
Article Type: Research Article
Received date: $18^{\text {th }}$ October, 2017
Accepted date: $19^{\text {th }}$ December, 2017
Published date: $28^{\text {th }}$ December, 2017
"Corresponding Author: Sung wan Hwang, Department of Health Administration, Baekseok Art University, Seoul, South
Korea. E-mail: healthgate@,bau.ac.kr
Citation: Kim C, Kim M, Yoon S, Hwang S (2017) Factors influencing anorexia in elderly patients in South Korea. J Pub
Health Issue Pract $1: 105$. https://doi.org/10.33790/jphip1100105.
Copyright: C2017, This is an open-access article distributed under the terms of the Creative Commons Attribution License
4.0, which permits unrestricted use, distribution, and reproduction in any medium, provided the original author and source are
credited.

\begin{abstract}
Introduction: Anorexia of ageing, described as a reduction in appetite or food intake in old age, is a significant contributing factor to poor nutrition and worse health outcomes in the geriatric population. Anorexia can affect a variety of medical conditions in the elderly. This study was undertaken to determine the factors affecting anorexia in this population.
\end{abstract}

Methods: We used several surveys to explore this subject, these included; the Simplified Nutritional Appetite Questionnaire(SNAQ), the Instrumental Activities of Daily Living(IADL), the Activities of Daily Living (ADL), the Mini Nutritional Assessment (MNA), the Korean version of the Mini Mental State Examination (K-MMSE) and the Geriatric Depression Scale (GDS). The study targeted outpatients of family medicine and cardiology clinics, residents of longterm care facilities, community health care promotion participants, and those living in social welfare facilities in Seoul, South Korea. We analyzed the risk factors that affect anorexia in the elderly. Basic statistical methods were used for analysis: Chi-square test (Fisher's exact test), student's t-test, and regression analysis.

Results: Our study showed that the prevalence of anorexia in nursing-home patients was higher than the other groups studied. The risk factors of impaired appetite and nutrition were related to the K-MMSE, MNA, and ADL from the cognitive and activities of daily living assessments. The results demonstrated that the issues contribut- ing to anorexia were nutrition management, psychological problems, and diminished physical activity.

Conclusion: Anorexia was found to be associated with problems with psychological well-being, impaired activities ofdaily living and poor nutrition. In the future, with a growing elderly population that is becoming less healthy it will be very important to focus on improving mental health care, nutrition management, and physical activity in order to reduce the impact of anorexia on medical problems in the elderly. Support isneeded from specialized community health care centers.

Keywords: Anorexia, Elderly, SNAQ, K-MMSE, MNA, ADL, Korean

\section{Introduction}

The issue of supporting the increasing elderly population is not only relevant to South Korea but also the rest of the world. Problems relating to aging and healthcare management issues arising from the health inequalities for current and future society. As the nation's aging population grows rapidly, attention is focused on caring for the elderly $[1,2]$. Achieving good health outcomes requires proper preventative care and treatments because of the impacts on the quality of life and poverty in the elderly. Anorexia is a phenomenon characterized by a decrease in appetite and physiological changes in response to nutrition demand in the elderly[1]. As aging progresses, individuals become less hungry and their food intake decreases [3]. Anorexia can cause muscle weakness, fatigue, impaired immune responses, mood changes such as depression and complications related to other chronic diseases [4, 5].

In a previous study, patients with anorexia showed double the mortality compared to healthy patients [5]. The aging process itself is considered a geriatric syndrome, a major turning point for disability and death in older people [6]. Anorexia is therefore an important issue and it is key to recognize because of the various negative effects on the elderly individuals health.

According to a study from Italy, it has been reported that 5-10\%of the elderly population living in the community had anorexia, with significantly more affected, $25-35 \%$,in the hospital setting[7]. There is however insufficient domestic research on the factors implicated in anorexia in the elderly in South Korea. In previous studies, anorexia showed that eating disorders affect food patterns, physical features, and weight loss[8-10]. The mainly factors previously studied in South Korea were Instrumental Activities of Daily Living (IADS) and Activities of Daily Living (ADL). In a clinical study, the nation reported factors relating to anorexia, treatment of anorexia, and countermeasures of anorexia [11-14].

Previous studies reported information about sources of nutrition or methods of treatment, but need research is still required to find preventable factors because anorexia can be influenced by several different causes. Recently, research has reported on the prevalence of anorexia, but did not include information from surveys such as the 
simplified nutritional appetite questionnaire (SNAQ). The SNAQ has been developed to measure the appetite status of elderly people living in residential and community settings, so it has the potential to complement the previously announced case study. The SNAQ is known as a useful way to assess the extent of anorexia [15]. Researchers have used the SNAQ questionnaire in recently studies[15-17]. However, there has so far been insufficient research in South Korea to measure anorexia in the elderly using SNAQ. The monitoring and exploration of anorexia in the elderly population is necessary because it is a major turning point for disability and premature death [6]. Our study was therefore aimed at finding out the potential factors affecting anorexia in elderly people in Seoul, South Korea.

\section{Materials and Methods}

\section{Study Subject}

This study was conducted on the elderly individuals aged 65 years or older who were recruited from outpatient clinics of the family medicine and cardiology departments in Seoul Metropolitan Government Medical Center in Seoul, long-term care facilities and community health care program participants in Jungnang-gu and Nowon-gu in Seoul, as well as social welfare facilities in Jungnanggu in Seoul, South Korea. The recruitment took place from March 2014 to October 2014.Among 195 participants, if the K-MMSE score is less than 10 points, it is excluded, and we analyzed 185 . Patients were classified with having anorexia $(\mathrm{N}=76)$ if they scored less than 14 points on the SNAQ and control subjects $(\mathrm{N}=109)$ scored more than 14 points for SNAQ[15]. This study was approved by the institutional review board (IRB) at Seoul Medical Center (IRB number SMC-2014-015). All patients provided informed written consent.

\section{Materials}

\section{The simplified nutritional appetite questionnaire}

The SNAQ was developed to measure the appetite of the elderly people living in the community. The SNAQ score helps evaluates their nutritional condition [17]. In addition, the SNAQ has the advantage of being short and simple to administer to communitydwelling adults and long term care residents[17]. The SNAQ questions are as follows:

1) My appetite (very poor $=\mathrm{a}$, poor $=\mathrm{b}$, average $=\mathrm{c}$, good $=\mathrm{d}$, very good=e),

2) I feel full after eating (only a few mouthfuls $=a$, about a third of a meal $=b$, over half a meal $=c$, most of the meal $=\mathrm{d}$, hardly ever feel full $=\mathrm{e}$ ),

3) Food tastes (very bad $=a$, bad $=b$, average $=c$, good $=d$, very good $=e$ ),

4) Number of meals per day $(<1$ meal a day=a, 1 meal a day $=$ b, 2 meals a day $=\mathrm{c}, 3$ meals a day $=\mathrm{d},>3$ meals a day $=\mathrm{e}$ ).

Points assigned for the patient's answers as follow: $a=1, b=2, c=3$, $\mathrm{d}=4, \mathrm{e}=5$.If the total SNAQ score was less than 14 points, it was evaluated as a risk group).

The SNAQ critical value is 14 points. In previous studies, it was found that the sensitivity to weight loss was higher when compared to scores above 14 points $[15,18,20]$. In these studies, if the SNAQ $<14$ points, the sensitivity and specific was low, but it was useful to predict general weight loss [15]. In addition, the SNAQ score was assessed based on 14 points of reference, increasing the incidence of hospitalization and mortality and identifying the severity of inpatients [20].

\section{General characteristics and anorexia factors}

The general characteristics examined were sex, age, smoking status, drinking (a week's experience in alcohol intake), physical activity (a week's experience in physical activity), patient type (outpatients, nursing homes patients), and systolic blood pressure (SBP), diastolic blood pressure (DBP). Blood pressure was measured twice and the average calculated. We also measured IADS, ADL [21], Mini Nutritional Assessment (MNA) [22], the Korean version of the MiniMental State Exam (K-MMSE) [23], and Geriatric Depression Scale (GDS) to deter- mine the factors affecting anorexia in the elderly [24].

\section{Statistics]}

The SNAQ was grouped into groups of 14 points or more and groups with 14 points. We performed a cross analysis to investigate the characteristics of SNAQ $<14$ groupand SNAQ $\geq 14$ group of the study subjects, and looked for statistical significance using students t-test and the chi-square test. A multiple regression analysis step was performed in order to identify factors influencing the SNAQ outcome scores. For all analyses, the signifi- cance level was set with a p-value below 0.05. PASW 20.0 (SPSS Inc., Chicago, IL, USA) was used to conduct the statistical analysis.

\section{Results}

\section{General Characteristics of the Subject}

Data on all 185 subjects was included in the analysis. Men constituted $24.9 \%(\mathrm{~N}=46)$ of the study population and women $75.1 \%(\mathrm{~N}=139)$. The average age was 75 years old. $4 \%(\mathrm{~N}=7)$ of the study population were active smokers. Alcohol drinking were 1.92 (range 1 - 2) times a week in the study population. The SBP averaged 126.9 (range 56 -198) $\mathrm{mmHg}$, while DBP averaged 70.8 (50 - 97) $\mathrm{mmHg}$. A total of 1.38 times of patients showed up physical activity during a week. Patient type showed outpatients $82.0 \%(\mathrm{~N}=150)$ and nursing homes patients showed $18.0 \%(\mathrm{~N}=33)$ in the study population.

The K-MMSE showed an average score of 25.85 (Min 11 to Max 30) points, GDS average score was 6.70 (Min 0 to Max 17) points. The IADL score was an average of 12.53 (Min 10 to Max 31) points, average ADL equaled 7.90 (Min 7 to Max 18) points and MNA average score was 10.99 (Min 3 to Max 17) points (Table 1).

\begin{tabular}{|l|l|l|l|l|l|}
\hline Variables & Classification & N & \% or Mean & Minimum & Maximum \\
\hline \multirow{3}{*}{ Sex } & Male & 46 & 24.9 & - & - \\
\cline { 2 - 7 } & Female & 139 & 75.1 & - & - \\
\hline Age & Years & 185 & 75.17 & 62 & 96 \\
\hline \multirow{3}{*}{ Smoking $(\mathrm{n}=175)$} & Smoking & 7 & 4.0 & - & - \\
\cline { 2 - 7 } & Ex-smoking & 35 & 20.0 & - & - \\
\cline { 2 - 7 } & Non-smoking & 133 & 76.0 & - & - \\
\hline Drinking $(\mathrm{n}=174)$ & & 174 & 1.92 & 1 & 2 \\
\hline
\end{tabular}




\begin{tabular}{|l|l|l|l|l|l|}
\hline \multirow{2}{*}{ Blood Pressure } & SBP & 185 & 126.92 & 56 & 198 \\
\cline { 2 - 6 } & DBP & 185 & 70.86 & 50 & 97 \\
\hline Physical Activity & & 169 & 1.38 & 1 & 2 \\
\hline \multirow{2}{*}{ Patient Type (n=183) } & Outpatients & 150 & 82.0 & - & - \\
\cline { 2 - 6 } & Nursing Homes Patients & 33 & 18.0 & - & \\
\hline Cognitive State & K-MMSE & 185 & 25.85 & 11 & 30 \\
\hline Depressive Symptoms & GDS & 185 & 6.70 & 0 & 17 \\
\hline Functional State & IADL & 185 & 12.53 & 10 & 31 \\
\cline { 2 - 6 } & ADL & 185 & 7.90 & 7 & 18 \\
\hline Nutritional Condition & MNA & 185 & 10.99 & 3 & 17 \\
\hline
\end{tabular}

Table 1 General Characteristics of the Subject

Abbreviations: SNAQ- Simplified Nutritional Appetite Questionnaire; SBP- Systolic Blood Pressure; DBP- Diastolic Blood Pressure; K-MMSE- Korean version of the Mini-Mental State Examination; GDS- Geriatric Depression Scale; IADLInstrumental Activities of Daily Living; ADL- Activities of Daily Living; MNA- Mini Nutritional Assessment.

Relationship between Geriatric Patient Characteristics and the SNAQ for the elderly

In terms of the SNAQ, $41.08 \%(\mathrm{~N}=76)$ of the SNAQ $<14$ group and $58.92 \%(\mathrm{~N}=109)$ of the $\mathrm{SNAQ} \geq 14$ group reported that were in the SNAQ. The SNAQ score was statistically correlated with K-MMSE $(\mathrm{p}=0.042)$ and MNA $(\mathrm{p}=0.008)$ (Table 2$)$.

\begin{tabular}{|c|c|c|c|c|}
\hline & & SNAQ $<14$ & SNAQ $\geq 14$ & \\
\hline \multirow[t]{2}{*}{ Variables } & \multirow[t]{2}{*}{ Classification } & $\mathrm{N}(\%)$ or Mean(SD) & $\mathrm{N}(\%)$ or Mean $(\mathrm{SD})$ & \multirow[t]{2}{*}{$\mathrm{t} / \mathrm{F}$ (p-value) } \\
\hline & & $\mathrm{N}=76$ & $\mathrm{~N}=109$ & \\
\hline \multirow[t]{2}{*}{ Sex } & Male & $15(32.6)$ & $31(67.4)$ & $1.816(0.23)$ \\
\hline & Female & $61(43.9)$ & $78(56.1)$ & \\
\hline Age & Years & $75.04(6.16)$ & $75.27(6.43)$ & $-0.242(0.81)$ \\
\hline \multirow[t]{3}{*}{ Smoking } & Smoking & $3(42.9)$ & $4(57.1)$ & $0.476(0.79)$ \\
\hline & Ex-smoking & $13(37.1)$ & $22(62.9)$ & - \\
\hline & Non-smoking & $58(43.6)$ & $75(56.4)$ & - \\
\hline \multirow[t]{2}{*}{ Blood Pressure } & SBP & $129.05(22.10)$ & $125.43(16.16)$ & $1.219(0.225)$ \\
\hline & DBP & $72.29(8.97)$ & $69.87(9.54)$ & $1.757(0.081)$ \\
\hline Drinking & & $1.93(0.25)$ & $1.91(0.29)$ & $0.491(0.624)$ \\
\hline Physical Activity & & $1.46(0.50)$ & $1.32(0.47)$ & $1.754(0.082)$ \\
\hline \multirow[t]{2}{*}{ Patient Type } & Outpatients & $64(42.7)$ & $86(57.3)$ & $0.443(0.506)$ \\
\hline & Nursing Homes Patients & $12(36.4)$ & $21(63.6)$ & - \\
\hline Cognitive State & K-MMSE & $25.09(4.82)$ & $26.39(3.77)$ & $4.152(0.042)$ \\
\hline Depressive Symptoms & GDS & $6.67(3.43)$ & $6.72(3.44)$ & $0.200(0.931)$ \\
\hline \multirow[t]{2}{*}{ Functional State } & IADL & $12.37(5.31)$ & $12.64(5.37)$ & $0.365(0.732)$ \\
\hline & $\mathrm{ADL}$ & $7.68(1.51)$ & $8.05(2.35)$ & $5.642(0.239)$ \\
\hline Nutritional Condition & MNA & $10.36(2.79)$ & $11.43(2.46)$ & $4.272(0.008)$ \\
\hline
\end{tabular}

Table 2 Relationship between Geriatric Patient Characteristics and the SNAQ for the elderly $(n=185)$

Abbreviations: SNAQ, Simplified Nutritional Appetite Questionnaire; SBP, Systolic Blood Pressure; DBP, Diastolic Blood Pressure; K-MMSE, Korean version of the Mini-Mental State Examination; GDS, Geriatric Depression Scale; IADL, Instrumental Activities of Daily Living; ADL, Activities of Daily Living; MNA, Mini Nutritional Assessment 


\section{Factors affecting the SNAQ}

The factors affecting the elderly individuals SNAQ scores were found to be the K-MMSE, the ADL, and the MNA. As the K-MMSE score increase, the SNAQ has increased by 1.12 (95\% CI 1.02-1.22) times, and the SNAQ has increased 1.45 (95\% CI 1.15-1.83) times as the ADL score increases by 1 point. As the MNA score increased, the SNAQ increased by 1.24 (95\% CI 1.08-1.43) times (Table 3).

\begin{tabular}{|c|c|c|c|c|c|}
\hline & & & $\begin{array}{l}\text { Crude Odds } \\
\text { Ratio }\end{array}$ & & $\begin{array}{l}\text { Adjusted Odds } \\
\text { Ratio* }\end{array}$ \\
\hline Variables & Classification & B & $\begin{array}{l}\text { (95\% Confidence } \\
\text { Interval) }\end{array}$ & B & $\begin{array}{l}\text { (95\% Confidence } \\
\text { Interval) }\end{array}$ \\
\hline \multirow[t]{2}{*}{ Sex } & Male & & 1 & - & - \\
\hline & Female & 0.480 & $0.62(0.31-1.25)$ & - & - \\
\hline Age & Years & 0.006 & $1.01(0.96-1.05)$ & - & - \\
\hline Physical Activity & & 0.567 & $0.57(0.30-1.07)$ & - & - \\
\hline \multirow[t]{2}{*}{ Patient Type } & Outpatients & & 1 & - & - \\
\hline & $\begin{array}{l}\text { Nursing Homes } \\
\text { Patients }\end{array}$ & 0.264 & $1.30(0.60-2.84)$ & - & - \\
\hline Cognitive State & K-MMSE & 0.071 & $1.07(1.00-1.15)$ & 0.109 & $1.12(1.02-1.22)$ \\
\hline Depressive Symptoms & GDS & 0.004 & $1.00(0.92-1.09)$ & - & - \\
\hline \multirow[t]{2}{*}{ Functional State } & IADL & 0.010 & $1.01(0.96-1.07)$ & - & - \\
\hline & ADL & 0.093 & $1.10(0.94-1.28)$ & 0.37 & $1.45(1.15-1.83)$ \\
\hline Nutritional Condition & MNA & 0.157 & $1.17(1.04-1.31)$ & 0.216 & $1.241(1.08-1.43)$ \\
\hline
\end{tabular}

Table 3. Factors affecting the SNAQ

Abbreviations: SNAQ, Simplified Nutritional Appetite Questionnaire; K-MMSE, the Korean version of the Mini Mental State Examination; GDS, Geriatric Depression Scale; IADL, Instrumental Activities of Daily Living; ADL, Activities of Daily Living; MNA, Mini Nutritional Assessment. *Adjusted for sex, K-MMSE, GDS, IADL, ADL and MNA

\section{Discussion}

Our study sought to evaluate the factors relating to anorexia in elderly people living in community and nursing home settings. Patients residing in nursing-home tended to experience moreanorexia than those from outpatient settings. The findings showed that the causes of anorexia was nutrition management, psychological problems, levels of cognition and lower physical activity. The factors to help lessen the onset of anorexia are thought to be better management of depression, oral care and drug problems[5, 25].

Previous studies have showed that neurotransmitters such as serotonin and CART (cocaine amphetamine-related transcript) can decrease appetite levels in elderly people[26]. Therefore Nerve diseases, Parkinson's disease, and stroke have all been linked to eating problems of appetite. The decline in sensory function caused by aging did not significantly reduce the amount of food. However, if these change were accumulated for a long time, this could result in significant weight loss [27]. However, neurophysiological rationale was not directly relevant to what has been shown in this on the causative factors.

According to studies of elderly people in Korea, anorexia indicated a higher prevalence of depression and dependency[11].Isolation and loneliness of elderly people are recognized to be important causes of anorexia and malnutrition. Our study examined GDS and K-MMSE, in relation to levels of anorexia and showed significant association with K-MMSE. This result suggests that aging may have affected the decrease in eating and mental health functions. According to the risk factors of the elderly for dysphagia using SNAQ, the risk groups showed mental problems in anorexia and reduced appetite, and were high risk in eating [28], And Depression was the most common cause in residential and nursing home [29]. Elderly patients with dementia showed an increase in appetite, but reduced portions of the diet quickly decreased as the disease progressed.

To prevent precipitation or exacerbation of disease in the elderly population, nutrition and psychological in- terventions are needed. In particular, physical activities can be carried out successfully and psychological health and nutrition interventions are also required. Previous studies have demonstrated the relevance of anorexia to ADL and IADL and supported that the correlation between SNAQ, ADL and IADL is significant. The findings of several studies impress the need to improve the appetites of elderly people and that this should be accompa- nied by increased physical activities[30-32]. Studies conducted for the elderly generally use both ADL and IADL tools; however, this study only showed significance in ADL possibly because the subjects involved elderly from among nursing home patients who was unable to live independently. If the study was conducted for elderly living in local communities, significant changes in IADL may be observed.

Our study used the SNAQ tool to determine the causative factors of anorexia in the elderly population. In previous study, the SNAQ was less relevant the MNA, however the critical value of the SNAQ was checked based on 14 points[15].Our results showed that the prevalence of anorexia was high when it scored 14 points as same thing compared with previous study reported findings.

Disadvantages of our study are that the study population was not selected by random sampling. The results of this studymaynotrepresent the prevalence of anorexia in the wider Korean elderly population. In addition, the validity and confidence of the questionnaires 
used was not ensured. For earlier detection of appetite problems, development of accurate validated tools and larger scale mass investigation will be needed.

We have shown that mental health, activities of daily life and dietary eating were the main factors causing anorexia in the Korean elderly. Anorexia often causes weight loss, therefore it is regarded as an important starting point of frailty syndromes, which are considered as a critical point on the pathway to disability and mortality. Further prospective studies are essential to determine the long-term consequences of anorexia assessed with SNAQ.

\section{Conclusions}

The purpose of this study was to determine factors affecting anorexia in the elderly population. Several variables were measured in 185 subjects aged 65 or older. After statistical analysis we concluded that nutrition management, psychological problems and physical activity are causative factors in the development of anorexia. The Korean population is growing older and becoming less healthy. It is important to identify and appropriately treat anorexia. This will be helped by improving the elderly's eating and living habits. We recommend that to prevent geriatric diseases, mental health, nutritional management and physical activity are required from community health promotion.

\section{Acknowledgments}

The research was funded by the Seoul Medical Center, Republic of Korea. This support is greatly appreciated.

\section{Conflict of Interest}

The authors have no conflicts of interest associated with the material presented in this paper.

\section{References}

1. Yoo HJ (1997) Geriatric diseases and medical service for the aged in Korea. Journal of the Korean Geriatrics Society 1: 6-11.

2. Yoo HJ (2014) Clinical implications of geriatric syndromes. J Korean Medical Association 57: 738-742.

3. Wurtman JJ (1988) The anorexia of aging: a problem not restricted to calorie intake. Neurobiology of aging 9: 22-23.

4. Martone AM, Onder G, Vetrano DL, Ortolani E, Tosato M, et al. (2013) Anorexia of aging: a modifiable risk factor for frailty. Nutrients 5: 4126-4133.

5. Landi F, Liperoti R, Russo A, Giovannini S, Tosato M, et al. (2013) Association of anorexia with sarcopenia in a communitydwelling elderly population: results from the ilSIRENTE study. Euro J Nutri 52:1261-1268.

6. Morley JE (2012) Anorexia of aging: a true geriatric syndrome. The J Nutri Health Age 16: 422-425.

7. Donini LM, Dominguez L, Barbagallo M, Savina C, Castellaneta $\mathrm{E}$, et al. (2011) Senile anorexia in different geriatric settings in Italy. The J Nutri Health Age 15: 775-781.

8. Donini LM, Poggiogalle E, Piredda M, Pinto A, Barbagallo M, et al. (2013) Anorexia and eating patterns in the elderly. PloS 8: e63539.

9. Landi F, Russo A, Liperoti R, Tosato M, Barillaro C, et al. (2010) Anorexia, physical function, and incident disability among the frail elderly population: Results from the ilSIRENTE study. J Am Med Direct Associat 11: 268-274.

10. Olsen-Noll CG, Bosworth MF (1989) Anorexia and weight loss in the elderly: causes range from loose dentures to debilitating illness. Postgraduate Med 85: 140-144.

11. Park S (2014) Appetite and Related Factors among Community Elders in Korea. J Korean Society of Food Science and Nutrition 43: $1431-1438$.
12. Park K, Kim M (2010) Treatment of anorexia of aging. Korean J Clin Geriatr 11: 45-53.

13. Kim M-Y (2014) Anorexia in the Elderly. Korean Journal of Clinical Geriatrics 15: 56-61.

14. Lee YH (1998) Anorexia in the Elderly. Journal of Korean Geriatric Psychiatry 2: 147-159.

15. Rolland Y, Perrin A, Gardette V, Filhol N, Vellas B (2012) Screening older people at risk of malnutrition or malnourished using the Simplified Nutritional Appetite Questionnaire (SNAQ): A comparison with the Mini-Nutritional Assessment (MNA) tool. J Am Medical Directors Association 13: 31-34.

16. Morley JE (2010) Anorexia, weight loss, and frailty. J Am Medical Directors Association 11: 225- 228.

17. Wilson M-MG, Thomas DR, Rubenstein LZ, Chibnall JT, Anderson S, et al. (2005) Appetite assessment: simple appetite questionnaire predicts weight loss in community-dwelling adults and nursing home residents. Am $\mathrm{J}$ of clini nutrition 82: 1074-1081.

18. Jagielak D, Wernio E, Kozaryn R, Bramlage P, GruchałaNiedoszytko M, et al. (2016) The impact of nutritional status and appetite on the hospital length of stay and postoperative complications in elderly patients with severe aortic stenosis before aortic valve replacement. Kardiochirurgia i torakochirurgia polska $=$ Polish journal of cardio-thoracic surgery 13: 105 .

19. Morley JE (2012) Undernutrition in older adults. Family Pract 29: i89-i93.

20. Pilgrim AL, Baylis D, Jameson K, Cooper C, Sayer AA, et al. (2016) Measuring appetite with the simplified nutritional appetite questionnaire identifies hospitalised older people at risk of worse health outcomes. J Nutr Health Aging 1-5.

21. Won CW, Rho YG, Kim SY, Cho BR, Lee YS (2002) The validity and reliability of Korean Activities of Daily Living (K-ADL) scale. J Korean Geriatrics Soc 6: 98-106.

22. Lee H, Kang JH, Kim E, Kim WG (2014) Prevalence of malnutrition in hospitalized elderly Korean patients based on mini nutritional assessment-short form. J Clin Nutr 6: 24-29.

23. Kang Y, Na DL, Hahn S (1997) A validity study on the Korean Mini-Mental State Examination (K-MMSE) in dementia patients. J Korean Neurolog Associat 15: 300-308.

24. Cho MJ, Bae JN, Suh GH, Hahm BJ, Kim JK, et al. (1999) Validation of geriatric depression scale, Korean version (GDS) in the assessment of DSM-III-R major depression. J Korean Neuropsychiat Associat 38: 48-63.

25. Landi F, Lattanzio F, Dell'Aquila G, Eusebi P, Gasperini B, et al. (2013) Prevalence and potentially reversible factors associated with anorexia among older nursing home residents: results from the ULISSE project. J Am Medical Directors Associat 14: 119124.

26. Kmiec Z (2011) Aging and peptide control of food intake. Current Protein and Peptide Science 12: 271-279.

27. Morley JE (2003) Anorexia and weight loss in older persons. The Journals of Gerontology Series A: Biological Sciences and Medical Sciences 58: M131-M137.

28. Park S (2015) Dysphagia risk and associated factors among community-dwelling elders. Journal of the Korean Society of Food Science and Nutrition 44: 49-56.

29. Morley JE (2010) Depression in nursing home residents. Journal of the American Medical Directors Association 11: 301-303. 
30. M Parlevliet JL, Buurman BM, Pannekeet MMH, Boeschoten EM, ten Brinke L, et al. (2012) Systematic comprehensive geriatric assessment in elderly patients on chronic dialysis: a cross-sectional comparative and feasibility study. BMC nephrology 13:30.

31. Ogundare OM, Shah VG, Salunke SR, Malhotra R, Pati S, et al. (2017) Fifteen Dimensions of Health and their Associations with Quality of Life among Elderly in Rural Villages in Maharashtra,(India). Ind J Geront 31.

32. Tufan A, Ozturk GB, Kilic C, Ilhan B, Muratli S, et al. (2014) Simplified Nutritional Appetite Questionnaire (SNAQ): an alternative test for geriatric nutritional assessment. Europ Geriatric Med 5: S183. 